\title{
An Empirical Study on the Influencing Factors of Farmers' Wage Income in Heilongjiang Province

\author{
Sha Lou ${ }^{1, a^{*}}$
}

${ }^{1}$ Harbin University of Commerce, Harbin China 150028

ae-mail: lousha1983@163.com

Keywords: Wage income; Influencing factors; Farmers; Security

\begin{abstract}
China's food security issue is related to national security. The quality of farmers' life is related to the orderly advancement of grain production. As a food province, Heilongjiang promotes farmers' income growth which is always the most important issue of all work. Farmers' wage income has become the main source of income in other provinces, so farmers' wage income is in urgent need of improvement in Heilongjiang. Based on the influencing factors of wage income, the paper analyzes the key factors to promote farmers' wage income.
\end{abstract}

\section{Introduction}

Family operating income is the main source of farmers' income in the main grain producing areas. Entering the 21st century, this situation has changed [1]. The main producing areas have been divided, for example, grain production income is still the main income of farmers in Heilongjiang, supplemented by wage income [2]. Based on the wage income, the paper studies the main factors that affect the wage income.

\section{Model selection}

The main goal of this section is to find the main influencing factors of wage income, which is suitable for multiple linear regression models. Specific models are as follows:

$$
Y=C+\beta_{1} X_{1}+\beta_{2} X_{2}+\ldots \ldots+\beta_{n} X_{n}+\varepsilon
$$

$\mathrm{Y}$ is the farmers' income increment, $\mathrm{C}$ is the constant term, $\beta \mathrm{n}$ is the regression coefficient of the corresponding variable, $\mathrm{Xn}$ is the corresponding variable, $\varepsilon$ is the random disturbance term, $\mathrm{n}$ is in the range of 1 to 6 .

\section{The Assuming Direction of Indicators}

The assumptions of indicators on farmers' wage income in Heilongjiang are as follows:

Table 1 the assuming direction of model variables

\begin{tabular}{lc}
\hline variables & The assuming direction \\
\hline $\mathrm{X}_{1}$ (labor quantity) & positive \\
$\mathrm{X}_{2}$ (culture quality of labor) & positive \\
$\mathrm{X}_{3}$ (labor age) & negative \\
$\mathrm{X}_{4}$ (working hours) & positive \\
$\mathrm{X}_{5}$ (mechanization rate) & positive \\
$\mathrm{X}_{6}$ (employment opportunities) & positive \\
$\mathrm{X}_{7}$ (traditional concept) & negative \\
\hline
\end{tabular}

\section{Data Selection and Feature Analysis}

The data of this part are mainly collected from the survey data. The survey involves 431 questionnaires. The specific data are shown in the following table: 
Table 2 the analysis of data

\begin{tabular}{cccccc}
\hline & $\mathrm{N}$ & Minimum & Maximum & Mean & Std. Deviation \\
\hline labor quantity & 431 & 1.00 & 5.00 & 2.5824 & .74213 \\
culture quality of & 431 & 1.00 & 4.30 & 3.0320 & .67962 \\
labor & & & & & \\
labor age & 431 & 28.00 & 70.00 & 40.8360 & 6.36396 \\
working hours & 431 & 4.67 & 11.67 & 7.8147 & 1.14302 \\
mechanization rate & 431 & .00 & 100.00 & 66.0209 & 31.71827 \\
employment & 431 & .00 & 1.00 & .3086 & .46245 \\
opportunities & & & & .3225 & .46798 \\
traditional concept & 431 & .00 & 1.00 & & \\
wage income & 431 & .00 & 91000.00 & 20444.7796 & 16888.89037 \\
Valid N (list wise) & 431 & & & & \\
\hline
\end{tabular}

\section{Analysis on Model Result}

Using SPSS software, the paper analyzes the survey data through the multiple linear regressions. The specific model analysis results are as follows:

From the model, we can see that $\mathrm{R}$ value is 0.647 , R2 is 0.419 , and after adjusted R2 is 0.409 . The results show that the fitting degree of the model test is acceptable, and it can reflect the relationship between the dependent variable and the independent variable. In addition, from the $\mathrm{F}$ test, $F$ value is 41.304 , the sig. value is 0.000 , indicating that the model passes the $F$ test, rejects the null hypothesis. It shows that there is a linear relationship between the independent variable and dependent variable in the model [3-5].

Table 3 Model Summary

\begin{tabular}{cccc}
\hline Model & $\mathrm{R}$ & $\mathrm{R}$ Square & Adjusted R Square \\
\hline 1 & $.647(\mathrm{a})$ & .419 & .409 \\
\hline
\end{tabular}

Table 4 ANOVA (b)

\begin{tabular}{ccccccc}
\hline Model & & Sum of Squares & df & Mean Square & F & Sig. \\
\hline 1 & Regression & 49796992089.224 & 7 & 7113856012.746 & 41.304 & $.000(\mathrm{a})$ \\
& Residual & 72853893664.837 & 423 & 172231427.104 & & \\
& Total & 122650885754.060 & 430 & & & \\
\hline
\end{tabular}

According to the results of the model, we can conclude that X1 (labor quantity), X2 (culture quality of labor), X4 (working hours), X5 (mechanization rate) and X6 (employment opportunities) have positive effects on wage income. The influence coefficients are 8063.825, 4271.896, 3524.028, 84.742 and 3989.168 respectively. Compared with the hypothesis, the direction of the above factors is basically the same as that of the hypothesis. X1 (labor quantity), X2 (culture quality of labor), X4 (working hours), X5 (mechanization rate) and X6 (employment opportunities), their corresponding sig. values are $0.000,0.000,0.000,0.000$ and 0.004 which are less than 0.05 . This indicates that they pass the $\mathrm{T}$ test. The above variables have a significant positive impact on $\mathrm{t}$ farmers' wage income. In addition, X3 (labor age) and X7 (traditional concept) have a negative impact on wage income. The influence coefficients are -132.176 and -4345.228 respectively. Compared with the hypothesis, the direction of the above factors is basically the same as that of the hypothesis. X3 (labor age) and X7 (traditional concept), their corresponding sig. values are 0.262 and 0.003 respectively. X3 (labor age) does not pass the 5\% confidence level t test, X7 (traditional concept) passes the $\mathrm{t}$ test of the 5\% confidence level [6-8]. This shows that the two variables have a negative 
effect on wage income, but the credibility of X3 (labor age) is relatively lower; while the credibility of X7 (traditional concept) is higher.

Table 5 Coefficients (a)

\begin{tabular}{lccccc}
\hline & \multicolumn{2}{c}{ Unstandardized Coefficients } & $\begin{array}{c}\text { Standardized } \\
\text { Coefficients Beta }\end{array}$ & $\mathrm{t}$ & Sig. \\
\hline (Constant) & -40897.473 & 8736.316 & & -4.681 & .000 \\
labor quantity & 8063.825 & 944.562 & .354 & 8.537 & .000 \\
culture quality of & 4271.896 & 1093.265 & .172 & 3.907 & .000 \\
labor & -132.176 & 117.615 & -.050 & -1.124 & .262 \\
labor age & 3524.028 & 590.755 & .239 & 5.965 & .000 \\
working hours & 84.742 & 20.140 & .159 & 4.208 & .000 \\
mechanization rate & 3989.168 & 1387.904 & .109 & 2.874 & .004 \\
employment & -4345.228 & 1432.600 & -.120 & -3.033 & .003 \\
opportunities & traditional concept & \multicolumn{1}{c}{ B } & & & Std. Error
\end{tabular}

According to the analysis results of the model, we can get the following regression equation:

$$
\begin{aligned}
& Y=-40897.473+8063.825 \mathrm{X}_{1}+4271.896 \mathrm{X}_{2}-132.176 \mathrm{X}_{3}+3524.028 \mathrm{X}_{4}+84.742 \mathrm{X}_{5} \\
& +3989.168 \mathrm{X}_{6}-4345.228 \mathrm{X}_{7}
\end{aligned}
$$

\section{Conclusions}

It can be seen from the final simulation equation that the factors influencing farmers' wage income are X1 (labor quantity), X2 (culture quality of labor), X4 (working hours) and X6 (employment opportunities), which have a greater positive impact and are the main promoting factors on family operating income. When X1 (labor force) increases by 1 person, wage income will grow 8063.825 Yuan. When X2 (labor education) rises in a level, wage income will grow 4271.896 Yuan. When X4 (working hours) increases by 1 month, wage income will grow 3524.028 Yuan. When there are more X6 (job opportunities), wage income will grow more than 3989.168 Yuan. X5 (mechanization rate) also contributes to wage income, but promotes less. When X5 (mechanization rate) increases by 1 unit, wage income will grow 84.742 Yuan. In addition, X3 (labor age) and X7 (traditional concept) have a restrictive effect on wage income. In contrast, X3 (labor age) has less restrictive effect on farmers' wage income, when the labor age increases 1 year, farmers' wage income will be reduced by 132.176 Yuan. When X7 (traditional concept) is strong, family operating income will be reduced by 4345.228 Yuan.

To sum up, according to the model research, it shows that the number of labor force, labor education, working hours and employment opportunities have a significant positive role in promoting for wage income[9]. The traditional conceptual factors have a significant negative effect on wage income. The remaining factors have little effect on wage income [10].

\section{Acknowledgments}

The paper is funded by the National Social Science Fund General Project "Research on Rural Financial Service Innovation and Risk Control in the Background of Agricultural Land Reform" (16BJL037).

\section{References}

[1] Mark Vallianatos, Robert Gottlieb and Margaret Ann Haase: Planning Education and Research, (2004) No.23, P.414-423.

[2] D.H. Zhang: Financial support, scale management and farmers' income in Heilongjiang Province. (China Fortune Press, China 2015).

[3] Z.F. Chen: Regional Economic Review, (2017) No.2, P.115-123. 
[4] X.R. Li and F. You: Chinese Agricultural Science Bulletin, (2017) No.5, P.139-145.

[5] B. Ru, Y.F. Yin and X.G. Xu: Rural economy, (2017) No.1, P.60-66.

[6] L.L.Yang and Q.Z. Lan: China Price, (2016) No.7, P.69.

[7] Y.M. Luo and L.M. Fan: Economic Research, (2015) No.8, P.146-161.

[8] J.X. Zhou: Financial research, (2015) No.8, P.50-63.

[9] S.S. Yang and Z.X. Zhang: Urban and Environmental Studies, (2015) No.2, P.74-90.

[10]N. Fang and K.F. Zhang: Statistics and Decision, (2015) No.10, P.137-139. 